Palavras chave:

Economia florestal Impostos

Taxa florestal Eucalipto

Histórico:

Recebido 03/02/2012

Aceito 14/04/2014

Keywords:

Forest economics

Taxes

Forest tax

Eucalyptus

Correspondência: christian_bsb@hotmail.com
Christian Rainier Imaña', Álvaro Nogueira de Souza², Humberto Ângelo², Márcio Lopes da Silva ${ }^{3}$, José Luiz Pereira Rezende ${ }^{4}$

\section{A TRIBUTAÇÃO NA PRODUÇÃO DE CARVÃO VEGETAL}

RESUMO: Nas últimas décadas, a carga tributária brasileira tem sido objeto de discussão no meio acadêmico. Em 2008, a relação Tributos/PIB atingiu o índice de países da OCDE, apesar de o Brasil encontrar-se socialmente em nível inferior aos referidos países. Realizouse, neste trabalho, uma análise na discriminação e quantificação dos tributos incidentes sobre a produção carvoeira. Onze tributos foram analisados: ECRRA, TF, COFINS, PIS, IRPJ, CSLL, ITR, TCFA, TFAMG, INSS e FGTS. O impacto tributário foi igual a $9,76 \%$ sobre o faturamento. Não houve incidência de tributos municipais. Os tributos estaduais representaram 10\% da carga tributária com predomínio da taxa florestal estadual, o restante da tributação é de competência federal. A COFINS foi o maior tributo: $3 \%$, corroborando a regressividade do sistema tributário brasileiro. Dentro do Estado de Minas Gerais, o ICMS do carvão vegetal é diferido, estando o produtor rural desobrigado de recolhê-lo, ficando essa responsabilidade a cargo dos adquirentes.

\section{TAXATION IN CHARCOAL PRODUCTION}

ABSTRACT: In past decades, the Brazilian tax burden has been the subject of discussion and analysis in the academic, political and social arena. In 2008, Brazilian tax burden reached the tax level from OECD countries, although the social issue in Brazil is in lower level than those countries. This paper has analyzed the tax burden from charcoal production. Eleven kinds of taxes were analyzed: IRPJ, ITR, CSLL, COFINS, PIS, TF, TCFA, TFAMG, ECRRA, INSS and FGTS. The tax burden for the production of charcoal was $9.76 \%$. There was no municipal tax for charcoal. State taxes accounted $10 \%$ of the tax burden, the rest are federal taxes. COFINS was responsible for the largest tax burden: $3 \%$, which confirms the Brazilian tax system is very non progressive. In Minas Gerais, Brazilian tax on goods and services (ICMS) is deferred, the charcoal buyer has the obligation to collect this tax. This means the steel company accounts for the total burden of ICMS.
' Secretaria de Estado de Fazenda de Minas Gerais - Belo Horizonte, Minas Gerais, Brasil

${ }^{2}$ Universidade de Brasília - Brasília, Distrito Federal, Brasil

${ }^{3}$ Universidade Federal de Viçosa - Viçosa, Minas Gerais, Brasil

${ }^{4}$ Universidade Federal de Lavras - Lavras, Minas Gerais, Brasil 


\section{INTRODUÇÃO}

Nas últimas décadas, a Economia Florestal tem ganhado relevante espaço nas discussões e pesquisas do mundo acadêmico. $O$ entrelaçamento das áreas de economia e de engenharia florestal tem propiciado uma nova abordagem da utilização dos recursos florestais, haja vista que a sustentabilidade econômica e a sustentabilidade sócio-ambiental são essenciais para o alcance de sucesso em empreendimentos florestais. A partir dos anos 60 , com a implantação do plano de incentivos fiscais para o setor florestal, o Brasil passou a ocupar lugar de destaque em relação ao seu grande potencial florestal, com a predominância no seu território de plantações de eucalipto e de pinus, que constituíram a denominada base florestal nacional. $O$ plano de benefícios fiscais da década de 60 propiciou que o país desenvolvesse o setor florestal, de modo que a área de floresta plantada aumentasse de 500 mil ha, em 1965, para 6,5 milhões ha, em 2010 (ASSOCIAÇÃO BRASILEIRA DE PRODUTORES DE FLORESTAS PLANTADAS - ABRAF, 20II). Apesar de a madeira ter perdido relevante espaço no mercado energético nacional nas últimas três décadas, ainda desempenha um importante papel na economia do país "em decorrência da demanda existente pelo produto no mercado siderúrgico" (BRITO; CINTRA, 2004). Dentro desse contexto, sobressai a importância tributárioeconômica do mercado florestal. De acordo com ABRAF (20II), o setor florestal foi responsáve, em 2010, por uma arrecadação tributária de mais de $\mathrm{R} \$ 7,4$ bilhões. O sistema tributário brasileiro mostra-se complexo e burocrático, cuja simples uniformização da apuração da sua carga tributária sequer consegue ser alcançada. Santos e Costa (2008) afirmam a existência de "controvérsia sobre - tamanho preciso da carga tributária bruta brasileira". Estimada em $34,85 \%$ do PIB nacional (INSTITUTO BRASILEIRO DE GEOGRAFIA E ESTATÍSTICA - IBGE, 2009) reflete o seu elevado percentual, que poderia ser, em tese, desvirtuado, haja vista que o país encontra-se na média dos demais países desenvolvidos (ORGANIZAÇÃO PARA A COOPERAÇÃO E DESENVOLVIMENTO ECONÓMICO - OCDE, 2010). Ademais, o sistema tributário brasileiro não ressalta a progressividade dos seus tributos. Pelo contrário, regressividade é a característica marcante da tributação brasileira, o que torna o sistema fiscal injusto, penalizando contribuintes de baixa capacidade econômico-contributiva. Em face ao exposto, objetivou-se, neste trabalho, comprovar se a tributação na produção do carvão vegetal aproxima-se do percentual de $34,8 \%$ da carga tributária brasileira, identificando e quantificando os respectivos tributos.

\section{MATERIAL E MÉTODOS}

Os dados foram obtidos a partir da Fazenda Bom Sucesso, pertencente ao Grupo Votorantim, localizada no município de Vazante, no Estado de Minas Gerais. Os dados da produção de carvão vegetal da empresa englobam os anos de 2007 a 201 I. Toda a produção de carvão vegetal é oriunda de floresta plantada.

A maior parte dos tributos federais e estaduais utiliza o faturamento (receita de vendas) como parâmetro de obtenção dos tributos a recolher. Impostos sobre a propriedade, taxas públicas e emolumentos são determinados em função de valores preestabelecidos nas legislações conexas, e outros (IRPJ e CSLL) necessitam, ainda, apurar o lucro real para obter os respectivos valores a recolher. Quanto ao IRPJ e CSLL, a legislação fiscal do Imposto de Renda fornece a possibilidade de apuração, por meio do lucro presumido, que considera o faturamento da empresa como base de cálculo. A principal razão de se adotar a sistemática do lucro presumido, ao invés do lucro real, deve-se à inviabilidade de obter-se dados ou de inferir-se as despesas e custos envolvidos na apuração do lucro real. Cumpre salientar que a empresa florestal analisada se insere dentro do limite de $R \$ 48$ milhões de faturamento/ano estipulado pela legislação fiscal para a apuração pelo lucro presumido.

Não se considerou a carga tributária incidente sobre insumos utilizados no processo de produção do carvão vegetal, o produtor florestal é consumidor final das mercadorias adquiridas e, consequentemente, arca com o ônus fiscal dos impostos indiretos.

Levou-se em consideração apenas os tributos dos quais a empresa analisada é sujeito passivo das respectivas obrigações. A análise abrangeu as espécies tributárias elencadas no ordenamento jurídico nacional, bem como as contribuições sociais destinadas ao financiamento da Seguridade Social que, apesar de não possuírem a natureza tributária no seu sentido estrito, serão consideradas nessa análise por representarem recolhimentos pagos, obrigatoriamente, ao tesouro público. Isso acompanha a análise da ótica macroeconômica e da contabilidade social, uma vez que a economia considera como contribuições ou tributos todos os recursos que ingressam nos cofres públicos, independentemente da sua definição jurídicodoutrinária ou da sua destinação (COÊLHO, 2009).

O carvão vegetal possui na jurisdição do território mineiro, um regime de tributação diferenciado no tocante ao principal imposto sobre consumo do país ICMS. Nas operações de venda realizadas por produtor rural localizado em Minas Gerais não incidirá o ICMS (MINAS GERAIS, 2002). Isto é, no Estado de Minas 
Gerais as operações de venda envolvendo carvão vegetal são diferidas no que tange ao recolhimento do ICMS. O diferimento tributário é um mecanismo fiscal que dispõe para uma determinada operação de venda a posteriori o pagamento do tributo devido. O Regulamento do ICMS do Estado de Minas Gerais, Decreto Estadual de Minas Gerais N. 43.080, de 13 de dezembro de 2002 (MINAS GERAIS, 2002a), dispõe no artigo I 48 que o pagamento do imposto incidente sobre a saída de carvão vegetal fica diferido, para o momento em que ocorrer a "saída de estabelecimento industrial situado no Estado, do produto resultante do processo de industrialização no qual tiver sido consumido".

Para cada tributo analisado procedeu-se com o seu respectivo cálculo, de acordo com o que dispunha a respectiva legislação.

O valor pago a título de Emolumento para cadastro, registro e renovação anual - ECRRA (MINAS GERAIS, 2002b) correspondeu a um valor anual. Dividiuse, para cada mês, o seu valor constante na legislação à razão de I/I2 (Tabela 1).

TABELA 1 Valores anuais e mensais de ECRRA (R\$). TABLE 1 Annual and monthly values for ECRRA (R\$).

\begin{tabular}{lccccc}
\hline & 2007 & 2008 & 2009 & 2010 & $2011^{1}$ \\
\hline ECRRA anual & 854,00 & 906,10 & $1.017,45$ & 999,55 & $1.090,65$ \\
ECRRA mensal & 71,00 & 75,51 & 84,79 & 83,30 & 90,89 \\
\hline
\end{tabular}

${ }_{1}^{1}$ Período analisado: Janeiro/2011 a Setembro/2011.

O valor pago a título de Taxa Florestal - TF (MINAS GERAIS, 1968) foi calculado, de acordo com o valor da UFEMG do ano corrente (Tabela 2). Utilizaramse os fatores de 0,56 e 2,8, de acordo com a legislação da TF para cada MDC de carvão vegetal proveniente, respectivamente, de floresta plantada e nativa (equações I e 2, sendo PC = Produção do carvão vegetal em MDC).

$\mathrm{TF}=\mathrm{PC} \cdot \mathrm{UFEMG} \cdot 0,56$ (floresta plantada)

$\mathrm{TF}=\mathrm{PC} \cdot \mathrm{UFEMG} \cdot 2,8$ (floresta nativa)

TABELA 2 Valores de UFEMG a serem considerados por ano de exercício.

TABLE 2 UFEMG's values per calendar year.

\begin{tabular}{lcc}
\hline Ato normativo & $\begin{array}{c}\text { Exercício de } \\
\text { competência }\end{array}$ & Valor (R\$) \\
\hline Resolução SEF 3.837/2006 & 2007 & 1,7080 \\
Resolução SEF 3.934/2007 & 2008 & 1,8122 \\
Resolução SEF 4.045/2008 & 2009 & 2,0349 \\
Resolução SEF 4.169/2009 & 2010 & 1,9991 \\
Resolução SEF 4.270/2010 & 2011 & 2,1813 \\
\hline
\end{tabular}

O valor pago a título da Contribuição para Financiamento da Seguridade Social - COFINS (BRASIL, 1991) foi calculado de acordo com a alíquota elencada para o carvão vegetal, conforme a equação 3 , sendo PC = Produção do carvão vegetal em MDC; PMC = Preço médio do carvão vegetal (ASSOCIAÇÃO MINEIRA DE SILVICULTURA - AMS, 20I0); e alíquota = 3\%.

COFINS $=$ PC $\cdot$ PMC $\cdot$ alíquota

O valor pago a título de Contribuição Social para o Programa de Integração Social - PIS (BRASIL, 1970) foi calculado de acordo com a alíquota elencada para o carvão vegetal, conforme a equação 4 , sendo $\mathrm{PC}=$ Produção do carvão vegetal em MDC; PMC = Preço médio do carvão vegetal (AMS, 20I0); e alíquota $=0,65 \%$.

$\mathrm{PIS}=\mathrm{PC} \cdot \mathrm{PMC} \cdot$ alíquota

O valor pago a título de Imposto de Renda da Pessoa Jurídica - IRPJ (BRASIL, 1999) foi calculado de acordo com a alíquota elencada para o carvão vegetal, conforme a equação 5, sendo PC = Produção do carvão vegetal em MDC; PMC = Preço médio do carvão vegetal $(A M S, 2010)$ e alíquota $=15 \%$. Se $(P C \times P M C)>R \$ 60$ mil então adicional $=10 \% \cdot 8 \% \cdot(P C \times P M C)$, senão adicional $=0$.

IRPJ (carvão vegetal $)=8 \% \cdot(P C \cdot P M C) \cdot$ alíquota + adicional

O valor pago a título de Contribuição social sobre o lucro líquido - CSLL (BRASIL, 1988) foi calculado de acordo com a alíquota elencada para o carvão vegetal, conforme a equação 6, sendo PC = Produção do carvão vegetal em MDC; PMC = Preço médio do carvão vegetal (AMS, 2010) e alíquota $=9 \%$.

CSLL $($ carvão vegetal $)=12 \% \cdot(P C \cdot P M C) \cdot$ alíquota

O valor pago a título de Imposto sobre Propriedade Territorial Rural - ITR (BRASIL, 2002) correspondeu a um valor anual (equação 7, sendo VTNT = Valor da terra nua tributável e alíquota $=$ $0,45 \%$ ). Dividiu-se, para cada mês, o seu valor venal da propriedade rural à razão de I/I 2 (Tabela 3).

ITR $=$ VTNT $\cdot$ alíquota 
TABELA 3 Valores anuais e mensais de ITR (R\$).

TABLE 3 Annual and monthly values for ITR (R\$).

\begin{tabular}{lccccc}
\hline & 2007 & 2008 & 2009 & 2010 & $2011^{1}$ \\
\hline VTNT & $18.733 .469,00$ & $19.882 .191,00$ & $18.680 .711,00$ & $18.642 .640,00$ & $20.098 .364,00$ \\
ITR anual & $84.301,00$ & $89.470,00$ & $84.063,00$ & $83.892,00$ & $90.443,00$ \\
ITR mensal & $7.025,00$ & $7.455,82$ & $7.005,27$ & $6.990,99$ & $7.536,89$ \\
\hline
\end{tabular}

${ }^{1}$ Período analisado: Janeiro/2011 a Setembro/2011.

O valor pago a título de Taxa de Controle e Fiscalização ambiental - TCFA (BRASIL, 2000) correspondeu a um valor anual. Dividiu-se, para cada mês, o valor constante na legislação à razão de I/I 2 (Tabela 4).

TABELA 4 Valores anuais e mensais de TCFA (R\$).

TABLE 4 Annual and monthly values for TCFA (R\$).

\begin{tabular}{|c|c|c|c|c|c|}
\hline & 2007 & 2008 & 2009 & 2010 & $2011^{1}$ \\
\hline TCFA anual & $1.440,00$ & $1.440,00$ & $1.440,00$ & $1.440,00$ & $1.440,00$ \\
\hline TCFA mensal & 120,00 & 120,00 & 120,00 & 120,00 & 120,00 \\
\hline
\end{tabular}

${ }_{1}^{1}$ Período analisado: Janeiro/2011 a Setembro/2011.

O valor pago a título de Taxa de Controle e Fiscalização Ambiental do Estado de Minas Gerais - TFAMG (MINAS GERAIS, 2003) correspondeu a um valor anual. Dividiu-se para cada mês o seu valor constante na legislação à razão de $\mathrm{I} / \mathrm{I} 2$ (Tabela 5 ).

TABELA 5 Valores anuais e mensais de TFAMG (R\$).

TABLE 5 Annual and monthly values for TFAMG (R\$).

\begin{tabular}{|c|c|c|c|c|c|}
\hline & 2007 & 2008 & 2009 & 2010 & $2011^{1}$ \\
\hline TFAMG anual & $2.160,00$ & $2.160,00$ & $2.160,00$ & $2.160,00$ & $2.160,00$ \\
\hline TFAMG mensal & 180,00 & 180,00 & 180,00 & 180,00 & 180,00 \\
\hline
\end{tabular}

O valor pago a título de Contribuição social do Fundo de Garantia por Tempo de Serviço - FGTS (BRASIL, 1990) considerou o número de funcionários (Tabela 6) e o valor do salário mínimo vigente à época (Tabela 7), acrescidos dos direitos de I/3 de férias e do $13^{\circ}$ salário (equação 8 , sendo alíquota $=8 \%$ ).
TABELA 6 Número de trabalhadores envolvidos na produção de carvão vegetal.

TABLE 6 Number of employees involved in the charcoal production.

\begin{tabular}{lccccc}
\hline & 2007 & 2008 & 2009 & 2010 & $2011^{1}$ \\
\hline Número de trabalhadores & 55 & 60 & 70 & 70 & 70 \\
\hline ' Período analisado: Janeiro/20I I a Setembro/20I I. & &
\end{tabular}

FGTS $($ carvão $)=\left(2,2\right.$ salários mín. $+1 / 3$ de férias $+13^{\circ}$ salário) $\cdot \mathrm{n}^{\circ}$ de trabalhadores · alíquota

O valor pago a título de Contribuição social do Instituto do Seguro Social - INSS (BRASIL, I99I) considerou o número de funcionários e o valor do salário mínimo vigente à época, acrescidos dos direitos de I/3 de férias e do $13^{\circ}$ salário (Tabelas 6 e 7), conforme a equação 9 , sendo a alíquota $=20 \%$.

INSS $($ carvão $)=\left(2,2\right.$ salários mín. $+1 / 3$ de férias $+13^{\circ}$ salário) $\cdot \mathrm{n}^{\circ}$ de trabalhadores · alíquota

\section{RESULTADOS E DISCUSSÃO}

$\mathrm{Na}$ Tabela 8, é apresentada a base de dados utilizada para a análise deste trabalho.

As onze espécies tributárias analisadas foram reunidas na Tabela 9, de modo a apresentar, resumidamente, suas bases de cálculo e alíquotas. Percebeu-se que alguns tributos não possuem alíquota, trata-se das taxas públicas: TF, TCFA e TFAMG. Inclui-se, também, nesse grupo o ECRRA, em face da obrigatoriedade de seu recolhimento, o que caracteriza

TABELA 7 Valores de salário mínimo entre 2007 e 2011.

TABLE 7 Minimum wage values, 2007-2011 (R\$).

\begin{tabular}{lll}
\hline Ato normativo & Valor (R\$) & Vigência \\
\hline Lei Federal N. 11.321, de 07 de julho de 2006 & 350,00 & $01 / 2007$ a 03/2007 \\
Lei Federal N. 11.498, de 28 de junho de 2007 & 380,00 & $04 / 2007$ a 02/2008 \\
Lei Federal N. 11.709, de 19 de junho de 2008 & 415,00 & $03 / 2008$ a 01/2009 \\
Lei Federal N. 11.944, de 28 de maio de 2009 & 465,00 & $02 / 2009$ a 12/2009 \\
Lei Federal N. 12.255, de 15 de junho de 2010 & 510,00 & $01 / 2010$ a 02/2011 \\
Lei Federal N. 12.382, de 25 de fevereiro de 2011 & 545,00 & $03 / 2011$ a 09/2011 \\
\hline
\end{tabular}

Fonte: Elaboração própria do autor. 
TABELA 8 Produção de carvão vegetal.

TABLE 8 Charcoal production.

\begin{tabular}{ccccccccc}
\hline Ano & Volume (MDC) & Preço $(\mathrm{R} \$)$ & Ano & Volume (MDC) & Preço (R\$) & Ano & Volume (MDC) & Preço (R\$) \\
\hline $01 / 2007$ & 2.960 & 107,26 & $08 / 2008$ & 18.622 & 185,69 & $03 / 2010$ & 19.074 & 112,00 \\
$02 / 2007$ & 3.550 & 117,30 & $09 / 2008$ & 18.030 & 177,53 & $04 / 2010$ & 18.456 & 129,00 \\
$03 / 2007$ & 4.855 & 114,16 & $10 / 2008$ & 18.706 & 126,66 & $05 / 2010$ & 19.078 & 134,00 \\
$04 / 2007$ & 7.535 & 115,07 & $11 / 2008$ & 15.652 & 90,73 & $06 / 2010$ & 18.643 & 121,00 \\
$05 / 2007$ & 7.750 & 109,13 & $12 / 2008$ & 15.825 & 79,83 & $07 / 2010$ & 19.318 & 110,00 \\
$06 / 2007$ & 5.595 & 104,16 & $01 / 2009$ & 16.940 & 85,21 & $08 / 2010$ & 19.505 & 95,00 \\
$07 / 2007$ & 5.550 & 102,85 & $02 / 2009$ & 15.300 & 85,36 & $09 / 2010$ & 18.886 & 96,00 \\
$08 / 2007$ & 4.770 & 103,75 & $03 / 2009$ & 11.700 & 84,24 & $10 / 2010$ & 19.155 & 99,00 \\
$09 / 2007$ & 6.968 & 101,65 & $04 / 2009$ & 8.700 & 70,27 & $11 / 2010$ & 18.820 & 102,00 \\
$10 / 2007$ & 12.770 & 97,79 & $05 / 2009$ & 9.400 & 70,86 & $12 / 2010$ & 19.125 & 103,00 \\
$11 / 2007$ & 12.206 & 100,73 & $06 / 2009$ & 17.400 & 76,65 & $01 / 2011$ & 19.383 & 145,00 \\
$12 / 2007$ & 12.144 & 100,39 & $07 / 2009$ & 9.700 & 77,59 & $02 / 2011$ & 17.500 & 145,00 \\
$01 / 2008$ & 13.514 & 99,39 & $08 / 2009$ & 15.500 & 88,13 & $03 / 2011$ & 19.145 & 147,50 \\
$02 / 2008$ & 12.501 & 101,15 & $09 / 2009$ & 16.514 & 92,78 & $04 / 2011$ & 18.400 & 151,75 \\
$03 / 2008$ & 15.532 & 114,51 & $10 / 2009$ & 18.600 & 100,18 & $05 / 2011$ & 20.000 & 152,50 \\
$04 / 2008$ & 17.823 & 125,72 & $11 / 2009$ & 18.058 & 104,47 & $06 / 2011$ & 19.500 & 151,75 \\
$05 / 2008$ & 18.579 & 143,24 & $12 / 2009$ & 18.193 & 102,44 & $07 / 2011$ & 20.285 & 139,37 \\
$06 / 2008$ & 17.788 & 155,18 & $01 / 2010$ & 19.558 & 104,00 & $08 / 2011$ & 20.092 & 131,80 \\
$07 / 2008$ & 18.601 & 179,24 & $02 / 2010$ & 17.230 & 107,00 & $09 / 2011$ & 20.188 & 121,99 \\
\hline
\end{tabular}

Fonte: Fazenda Bom Sucesso, Grupo Votorantim (2007-20I I).

TABELA 9 Bases de cálculo e alíquotas dos tributos envolvidos na produção de carvão vegetal.

TABLE 9 Tax calculation basis and tax rates involved in the charcoal production.

\begin{tabular}{lcc}
\hline Tributos & Base de Cáculo & Alíquota \\
\hline ECRRA & Lei Estadual 14.309/2002 & Sem alíquota \\
TF & Produção de carvão vegetal & 0,56 UFEMG/MDC \\
COFINS & Faturamento & $3 \%$ \\
PIS & Faturamento & $0,65 \%$ \\
IRPJ & $8 \%$ do facturamento & $15 \%$ \\
CSLL & $12 \%$ do facturamento & $9 \%$ \\
ITR & Valor da terra nua tributável & $0,45 \%$ \\
TCFA & Lei Federal N. 10.165/2000 & Sem alíquota \\
TFAMG & Lei Estadual N. 14.940/2003 & Sem alíquota \\
FGTS & Folha de pessoal & $8 \%$ \\
INSS & Folha de pessoal & $20 \%$ \\
\hline
\end{tabular}

seu caráter de taxa pública, haja vista que o Estado está prestando serviço público de cadastro da empresa, sob responsabilidade do Instituto Estadual de Florestas de Minas Gerais. A variável faturamento representou importante ferramenta de trabalho, considerando que constitui a base de cálculo da maioria dos tributos. Os tributos relacionados ao patrimônio (ITR e IPTU) têm suas bases de cálculo de acordo com o valor de venda das respectivas propriedades rural e urbana. A TF considera o volume produzido de carvão vegetal, diferenciandose das outras duas taxas, que têm seus valores pré-determinados, nas sua respectivas legislações, independentemente da quantidade produzida.

A alíquota do IRPJ incidente sobre o faturamento foi I,2\% (15\% sobre $8 \%$ do faturamento) no caso da base de cálculo ser inferior a $\mathrm{R} \$ 60$ mil; nos casos em que a base de cálculo foi maior do que $R \$ 60 \mathrm{mil}$ somou-se ao IRPJ um valor adicional de $10 \%$ da base de cálculo encontrada, resultando em $2 \%$ (I5\% sobre $8 \%$ do faturamento $+10 \%$ sobre $8 \%$ do faturamento). Já, a alíquota da CSLL incidente sobre o faturamento foi I,08\% (9\% sobre 12\% do faturamento). Delineou-se, na Figura 1, a participação de cada um dos tributos.

De acordo com a Figura 2, a taxação estadual concentra-se, praticamente, na respectiva TF. Isso é, as demais taxas públicas estaduais: TCFA e ECRRA não possuem representatividade quanto ao aspecto arrecadatório, sendo quase nulas. Sem incidência de nenhum tributo municipal, notou-se que a concentração da carga tributária do carvão vegetal se deu quase toda no pólo federal com a predominância da COFINS, representando $3 \%$ do faturamento. Observou-se que $1,63 \%$ e $0,97 \%$ do faturamento foi para recolher encargos sociais e taxa florestal, respectivamente. 


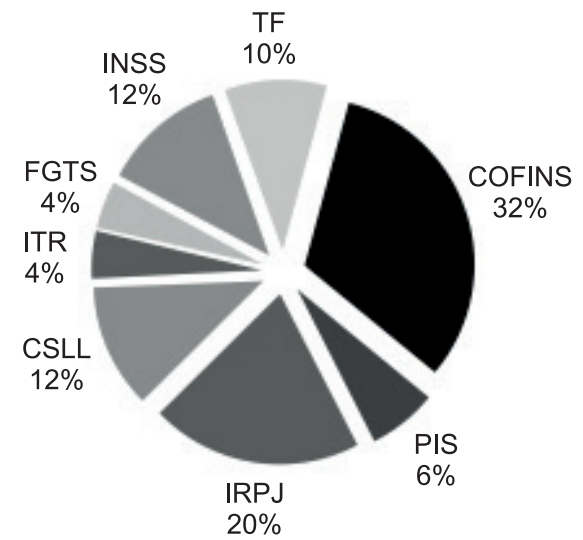

FIGURA 1 Distribuição da carga tributária na produção de carvão vegetal.

FIGURE 1 Division from charcoal tax burden in the charcoal production.

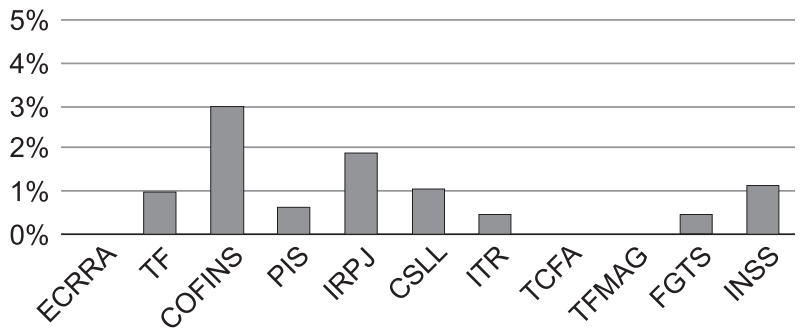

FIGURA 2 Carga tributária na produção de carvão vegetal. FIGURE 2 Charcoal tax burden in the charcoal production.

Agruparam-se, na Figura 3 , os tributos pesquisados em 5 grupos: tributos indiretos (COFINS, PIS), tributos diretos (IRPJ, CSLL), encargos sociais (FGTS, INSS), taxas públicas (ECRRA, TF, TCFA, TFAMG) e tributo sobre propriedade (ITR).

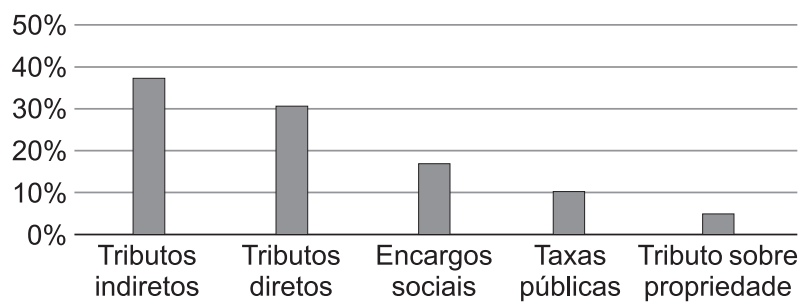

FIGURA 3 Distribuição da carga tributária na produção de carvão vegetal por grupo de tributos.

FIGURE 3 Division from the charcoal tax burden by group of taxes.

Da carga tributária incidente sobre o processo carvoeiro, a maioria é resultante dos tributos indiretos e, em segundo plano, aparecem os tributos diretos, incidentes sobre o lucro. A predominância da tributação indireta, calcada nos tributos incidentes sobre as vendas, retrata a regressividade que se alastra pelo sistema fiscal brasileiro. Simulou-se o caso do carvão ser de mata nativa (Figura 4). O fator de cálculo para carvão de mata nativa é cinco vezes maior do que para o caso de floresta plantada.

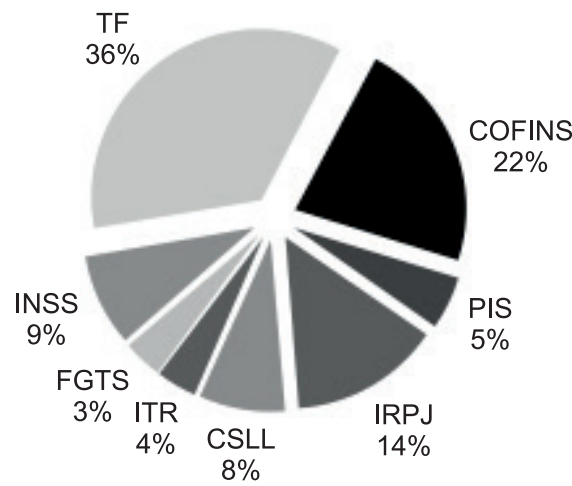

FIGURA 4 Distribuição da carga tributária na produção de carvão vegetal de floresta nativa.

FIGURE 4 Division from charcoal tax burden in the charcoal production from native forest.

Observou-se mudança na carga tributária incidente sobre um eventual carvão vegetal vindo de mata nativa. O Governo de Minas Gerais impõe alta taxação para carvão de mata nativa, haja vista que a taxa florestal passa a ser o maior tributo incidente na produção do carvão, superando a COFINS, que é o maior tributo do carvão de floresta plantada. Pode-se afirmar que, o produtor rural de floresta plantada detém uma espécie de incentivo fiscal, uma vez que se o mesmo produtor rural colhesse carvão vegetal de mata nativa estaria pagando maior valor de taxa florestal.

A TCFA e TFAMG são taxas idênticas, compartilham dos mesmos elementos de fato gerador, de sujeição passiva, de base de cálculo e de alíquota. O valor que se recolhe pelas duas taxas é igual a $3.600,00 \mathrm{R} \$ \cdot \mathrm{ano}^{-1}$. Esse valor se torna imperceptível ante o montante de carvão produzido. Isto é, não existe nenhuma significação arrecadatória para essas duas taxas ambientais. As duas taxas tampouco conseguem inibir um eventual abuso na exploração dos recursos florestais. Uma explicação para esse baixo valor de taxa de fiscalização ambiental reside no fato da Constituição Federal de 1988 vedar a existência de taxas públicas, inclusive de natureza ambiental (a instituição de tributos na área ambiental se deve a intentar impedir ou, ao menos, reduzir externalidades negativas existentes naquele setor produtivo. Isto é, ao se cobrar tributos na área ambiental, deduz-se que o objetivo seja reduzir os efeitos danosos que a prática daquela empresa causa ao meio ambiente), que possuam a mesma base de cálculo 
de qualquer imposto já existente. É proibido, a qualquer ente político, instituir taxa pública que tenha como base de cálculo o faturamento ou o lucro, uma vez que incidem sobre tais bases o ICMS e o IRPJ.

A incidência dos encargos sociais (INSS e FGTS) ficou num nível superior ao das taxas públicas. Os encargos sociais são mais nocivos sob a ótica rentábil e trabalhista, já que no momento em que a receita de vendas diminui o seu peso relativo aumenta, pois salários independem da produção.

Observou-se que, $90 \%$ dos valores pagos são de competência federal e os $10 \%$ restantes são de competência estadual (Figura 5).

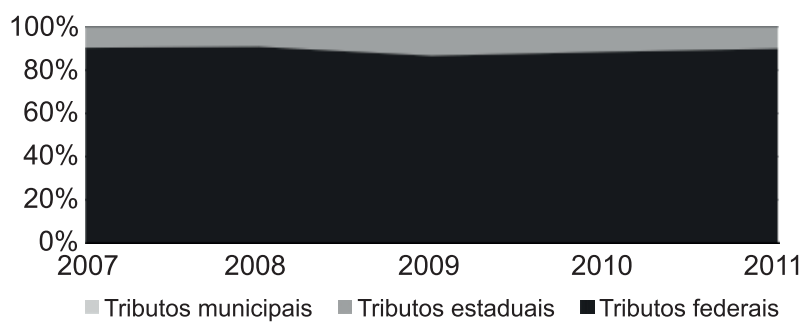

FIGURA 5 Distribuição da carga tributária na produção de carvão vegetal por esfera política.

FIGURE 5 Division from charcoal tax burden by federative sphere.

Não há, portanto, incidência de tributação municipal. Isso corrobora com a baixa participação dos tributos municipais sobre a carga tributária brasileira. Cumpre salientar que, a predominância da arecadação federal sobre a estadual, deve-se ao fato do ICMS não incidir sobre a produção do carvão vegetal.

\section{CONCLUSÕES}

A hipótese da carga tributária do carvão vegetal encontrar-se próxima à carga tributária brasileira de $34,85 \%$ foi rejeitada diante da não incidência do ICMS, o que resultou numa incidência fiscal de $9,76 \%$ sobre o faturamento. Consequentemente, se está diante de incentivo fiscal ofertado ao setor florestal pelo Estado de Minas Gerais. Regressividade é a maior característica do sistema tributário, com predominância dos tributos indiretos. Uma nova política de incentivos fiscais para o setor florestal traria mais ganhos para os empreendimentos florestais, se fosse idealizada sobre a redução da COFINS e PIS sobre faturamento, ao invés de o governo ofertar incentivos fiscais para IRPJ e CSLL, em face do conjunto das alíquotas dos tributos indiretos (COFINS e PIS) ser maior do que no caso dos tributos diretos (IRPJ e CSLL).

\section{REFERÊNCIAS}

ASSOCIAÇÃO BRASILEIRA DE PRODUTORES DE FLORESTAS PLANTADAS. Anuário estatístico da ABRAF: ano base 2010. Brasília, 201 I.

ASSOCIAÇÃO MINEIRA DE SILVICULTURA. Anuário estatístico Associação Mineira de Silvicultura 2010, ano base 2009. Belo Horizonte, 2010.

BRASIL. Decreto Federal $\mathbf{n}^{\circ} \mathbf{3 . 0 0 0}$, de 26 de março de 1999. Regulamenta a tributação, fiscalização, arrecadação e administração do Imposto sobre a Renda e Proventos de Qualquer Natureza. Brasília, 1999. Disponível em: <http:// www.planalto.gov.br/ccivil_03/Decretos/D3000.htm >. Acesso em: 13 dez. 2013.

BRASIL. Lei Complementar Federal $\mathbf{n}^{\circ}$ 07, de 7 de setembro de 1970. Institui o Programa de Integração Social, e dá outras providências. Brasília, 1970. Disponível em: <http:// www.planalto.gov.br/ccivil_03/Leis/L07.htm > . Acesso em: $13 \mathrm{dez} .2013$.

BRASIL. Lei Complementar Federal $\mathbf{n}^{\circ} \mathbf{7 0}$, de 30 de dezembro de 1991. Institui contribuição para financiamento da Seguridade Social, eleva a alíquota da contribuição social sobre o lucro das instituições financeiras e dá outras providências. Brasília, 1991. Disponível em: <http://www.planalto.gov. br/ccivil_03/Leis/L70.htm>. Acesso em: I 3 dez. 2013.

BRASIL. Lei Federal $\mathbf{n}^{\circ}$ 4.382, de 19 de setembro de 2002. Regulamenta a tributação, fiscalização, arrecadação e administração do Imposto sobre a Propriedade Territorial Rural - ITR. Brasília, 2002. Disponível em: <http://www. planalto.gov.br/ccivil_03/Leis/L4382.htm>. Acesso em: 13 dez. 2013.

BRASIL. Lei Federal $\mathbf{n}^{\circ} \mathbf{7 . 6 8 9}$, de 15 de dezembro de 1988. Institui contribuição social sobre o lucro das pessoas jurídicas e dá outras providências. Brasília, 1988. Disponível em:<http://www.planalto.gov.br/ccivil_03/Leis/L7689. htm>. Acesso em: 13 dez. 2013.

BRASIL. Lei Federal $\mathbf{n}^{\circ} \mathbf{8 . 0 3 6}$, de I I de maio de I 990. Dispõe sobre o Fundo de Garantia do Tempo de Serviço, e dá outras providências. Brasília, 2000. Disponível em: <http:// www.planalto.gov.br/ccivil_03/Leis/L8063.htm>. Acesso em: 13 dez. 2013.

BRASIL. Lei Federal $\mathbf{n}^{\circ} \mathbf{8 . 2} 12$, de 24 de julho de I99I. Dispõe sobre a organização da Seguridade Social, institui Plano de Custeio, e dá outras providências. Brasília, 2000. Disponível em:<http://www.planalto.gov.br/ccivil_03/Leis/ L82I2.htm>. Acesso em: I3 dez. 2013.

BRASIL. Lei Federal $\mathbf{n}^{\circ} \mathbf{1 0 . 1 6 5}$, de 27 de dezembro de 2000. Altera a Lei $n^{\circ} 6.938$, de 3 I de agosto de I 98I, que dispõe sobre a Política Nacional do Meio Ambiente, seus fins e mecanismos de formulação e aplicação, e dá outras providências. Brasília, 2000. Disponível em: <http://www.planalto.gov.br/ccivil_03/ Leis/LI0I65.htm>. Acesso em: I3 dez. 2013. 
BRITO, J. O. B.; CINTRA, T. C. Madeira para energia no Brasil: realidade, visão estratégica, demanda de ações. Biomassa e Energia, São Paulo, v. I, n. 2, p. I57163, 2004.

COÊLHO, S. C. N. Curso de direito tributário. Rio de Janeiro: Forense, 2009.

INSTITUTO BRASILEIRO DE GEOGRAFIA E ESTATÍ́STICA. Perfil do municípios brasileiros. Brasília, 2009.

MINAS GERAIS. Decreto Estadual $n^{\circ}$ 43.080, de 13 de dezembro de 2002. Aprova o Regulamento do Imposto sobre Operações Relativas à Circulação de Mercadorias e sobre Prestações de Serviços de Transporte Interestadual e Intermunicipal e de Comunicação (RICMS). Belo Horizonte, 2002a. Disponível em: <http://www. almg.gov.br/consulte/legislacao/completa/completa. html?tipo $=$ DEC\&num $=43080 \&$ comp $=\& a n o=2002>$. Acesso em: 10 dez. 2013.

MINAS GERAIS. Lei Estadual $\mathbf{n}^{\circ} \mathbf{4 . 7 4 7}$, de 9 de maio de 1968. Dispõe sobre a cobrança das Taxas Estaduais. Belo Horizonte, 1968. Disponível em: <http://www. almg.gov.br/consulte/legislacao/completa/completa. html?tipo $=$ LEI\&num $=4747 \&$ comp $=\&$ ano $=1968>$. Acesso em: 10 dez. 2013.
MINAS GERAIS. Lei Estadual $n^{\circ}$ 14.309, de 19 de junho de 2002. Dispõe sobre as políticas florestal e de proteção à biodiversidade no Estado. Belo Horizonte, 2002b. Disponível em: <http://www. almg.gov.br/consulte/legislacao/completa/completa. html?tipo $=$ LEl\&num $=\mid 4309 \&$ comp $=\& a n o=2002>$. Acesso em: $10 \mathrm{dez} .2013$.

MINAS GERAIS. Lei Estadual $\mathbf{n}^{\circ} \mathbf{1 4 . 9 4 0}$, de 20 de dezembro de 2003. Institui o Cadastro Técnico Estadual de Atividades Potencialmente Poluidoras ou Utilizadoras de Recursos Ambientais e a Taxa de Controle e Fiscalização Ambiental do Estado de Minas Gerais TFAMG e dá outras providências. Belo Horizonte, 2003. Disponível em: <http://www. almg.gov.br/consulte/legislacao/completa/completa. html?tipo $=$ LEI\&num $=\mid 4940 \&$ comp $=\& a n o=2003$. Acesso em: 10 dez. 2013.

\section{ORGANIZAÇÃO PARA A COOPERAÇÃO E} DESENVOLVIMENTO ECONÓMICO. Revenue statistics: comparative tables, OCDE tax statistics. Paris, 2010.

SANTOS, C. H. dos; COSTA, F. R. Uma metodologia de estimação da carga tributária bruta brasileira em bases trimestrais. Economia Aplicada, Rio de Janeiro, v. I2, n. 4, p. 209-235, 2008. 